\title{
Severe Aplastic Anemia in a Patient with Erythropoietic Protoporphyria Successfully Treated by Avatrombopag
}

\section{ZIMING JIANG}

Peking Union Medical College Hospital

\section{Xianyong Jiang}

Peking Union Medical College Hospital

Miao Chen ( $\nabla$ chenm@pumch.cn )

Peking Union Medical College Hospital https://orcid.org/0000-0002-8002-6651

\section{Research Article}

Keywords: Erythropoietic protoporphyria, Severe aplastic anemia, Avatrombopag, Hepatotoxicity, Liver dysfunction

Posted Date: September 17th, 2021

DOl: https://doi.org/10.21203/rs.3.rs-879502/v1

License: (9) This work is licensed under a Creative Commons Attribution 4.0 International License. Read Full License

Version of Record: A version of this preprint was published at Annals of Hematology on November 26th, 2021. See the published version at https://doi.org/10.1007/s00277-021-04726-2. 


\section{Abstract}

Erythropoietic protoporphyria (EPP) is a rare autosomal recessive disease presented with protoporphyrin deposition, photosensitivity and even liver damage. Avatrombopag, a thrombopoietin receptor agonists, has been applied for immune thrombocytopenia and periprocedural thrombocytopenia in patients with chronic liver disease. Here, we reported the first case of a 19-year-old man with acquired aplastic anemia associated with congenital EPP. EPP has led to a severe cirrhosis and liver dysfunction in this patient, which limited hematopoietic stem cell transplantation and immunosuppressive therapy to cure aplastic anemia. We administered Avatrombopag as the first-line therapy. After 8 months, we observed that avatrombopag induced complete response of aplastic anemia safely.

\section{Introduction}

Erythropoietic protoporphyria (EPP) is a rare autosomal recessive disease characterized by a deficiency of the enzyme ferrochelatase ( $\mathrm{FECH})$, which caused protoporphyrin deposition and photosensitivity. The excess protoporphyrin is excreted by the liver and may induce liver damage. About $20 \%$ of patients with EPP develop liver dysfunction, and $2-5 \%$ of them progress to cirrhosis and liver failure with a very poor prognosis $^{[1-2]}$. No aplastic anemia associated with congenital EPP has been reported to date. Here, we report a case of severe aplastic anemia in a congenital EPP patient. The dosage of cyclosporine A (CsA) is limited for the patient due to EPP associated liver fibrosis and avatrombopag induced complete response of aplastic anemia safely.

\section{Case Presentation}

In Oct 2019, a 19-year-old man was admitted to our hospital with liver dysfunction. He has hypersensitivity of skin to sunlight since childhood. Liver function tests demonstrated elevated liver enzymes (alanine aminotransferase, ALT 206U/L,aspartate aminotransferase, AST 81U/L, Y-glutamyl

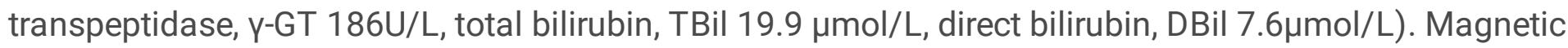
resonance imaging indicated liver fibrosis, broadened portal vein, portal hypertension and splenomegaly. Liver puncture pathology revealed significant cholestasis of hepatocytes and bile ducts with liver fibrosis, biliary cast in the capillary bile ducts and activated Kupffer cells presented as malts cross under polarized light, which is protoporphyrin crystal. Blood testing showed zinc protoporphyrin in erythrocyte was $8.8 \mathrm{ug} / \mathrm{g} \mathrm{Hb}$ (normal, 0-4.7). Total protoporphyrin in erythrocytes was not detected. Urinary porphyrin and uroporphyrinogen were negative. The next generation sequencing (NGS) revealed a double heterozygous FECH mutation (c.1156-1G > A, c.315-48T > C) inherited from his parents. Otherwise, blood routine showed that leukocyte count (WBC) was $4.72 \times 10^{9} / \mathrm{L}$ with a normal differential count, hemoglobin concentration $(\mathrm{Hb})$ was $137 \mathrm{~g} / \mathrm{L}$, and platelet count $(\mathrm{PLT})$ was $121 \times 10^{9} / \mathrm{L}$. This patient was diagnosed with congenital erythropoietic protoporphyria with liver fibrosis. Polyunsaturated phosphatidylcholine and diammonium glycyrrhizinate were provided to protect hepatocytes from toxic damage. 
In July 2020, the patient was presented with fatigue and low fever for one week. Blood routine displayed $\mathrm{Hb}$ of $55 \mathrm{~g} / \mathrm{L}$, reticulocyte absolute value of $20 \times 10^{9} / \mathrm{L}$, with WBC of $2.24 \times 10^{9} / \mathrm{L}$ and PLT of $18 \times 10^{9} / \mathrm{L}$. Bone marrow (BM) punctures of posterior superior iliac spine were performed twice. Both BM aspirate smear showed hypocellularity and trephine biopsy showed overly hypoplasia, cavitas medullaris filled with adipocytes and no megakaryocyte was found (Fig. 1A-C). Chromosomal karyotype was 46, XY [20] and no gene mutation associated with AML/MPN/MDS was detected by NGS. The results of liver function tests were within normal limits during the period. Ferritin, folic acid and vitamin B12 were not deficient. CMV-DNA, EBV-DNA were negative. Paroxysmal nocturnal hemoglobinuria (PNH) clone was detected by flow cytometry. PNH granulocyte clone sizes were $4 \%$ and $2 \%$ using the FLEAR and CD 59based assays respectively. PNH erythrocyte clone sizes both were $2 \%$ for the CD59 and CD55-based assays respectively. Severe aplastic anemia (AA) with $\mathrm{PNH}$ clone was diagnosed.

The patient has no sibling donor to perform hematopoietic stem cell transplantation (HSCT). Liver fibrosis also placed restrictions on allo-transplantation and intensive immunosuppressive treatment of antithymocyte globulin (ATG). He was started on cyclosporin A (CsA, 75mg twice-daily) with a trough concentration of CsA was only $34.7 \mathrm{ng} / \mathrm{ml}$. The dosage of CsA increased to $125 \mathrm{mg}$ twice-daily and the trough concentration of CsA was just $115.2 \mathrm{ng} / \mathrm{ml}$. Limited by the potential hepatotoxicity, it is difficult to increase the CsA dose. Therefore, we initiated avatrombopag therapy (20mg once-daily). After 5 months, his $\mathrm{Hb}$ increased to $123 \mathrm{~g} / \mathrm{L}$ and platelet counts recovered to $103 \times 10^{9} / \mathrm{L}$ (Fig. 2A-B). Avatrombopag was reduced to $20 \mathrm{mg}$ once every other day for 3 months and then stopped. The patient kept response with a low dose of CsA (75mg twice-daily) and the liver function tests remained stable during the whole course (Fig. 2C-G).

Mild microcytic anemia with low ferritin can be seen in EPP patients though the mechanism of iron deficiency is unclear ${ }^{[1]}$. But no aplastic anemia has been described. The patient presented pancytopenia at 20 years old without any deformity of body. He had no family history of bone marrow failure disease and no germline gene mutation associated with congenital AA had been detected by next generation sequencing. So, he was diagnosed as acquired AA. The detection of a PNH clone also supported the judgement. T Shirota ${ }^{[3]}$ reported a case of acquired EPP following myelodysplastic syndrome (MDS) with the history of 15-years AA and stem cells defects of the heme biosynthesis in MDS are thought to lead to the development of EPP. But based on our knowledge, this is the first reported case of AA with congenital EPP. Acquired AA is characterized by pancytopenia and bone marrow hypoplasia, which results from immune-mediated hematopoiesis suppression. No immune injury has been assessed in EPP patients.

Most EPP patients manifest as photodermatoses and need sun-protection. But deposition of protoporphyrin crystals in hepatocytes and bile canaliculi causes progressive liver damage in a minority of patients. Some therapeutic approaches have been adopted for liver disease of EPP, such as attempts to induce bile flow by ursodeoxycholic acid, to protect hepatocytes from toxic damage by $\mathrm{N}$-acetyl cysteine, and to interrupt the enterohepatic circulation by cholestyramine ${ }^{[5]}$. But none of these has been shown to be unequivocally efficacious. And it is also important to avoid alcohol and drugs that harm the 
liver. EPP patients of end-stage liver disease should considered liver transplantation and even HSCT to prevent recurrence of hepatic disease.

Treatment options for severe AA include HSCT and immunosuppressive therapy (IST) ${ }^{[6]}$. Both EPP and severe AA can be cured by HSCT. However, liver fibrosis and lack of sibling-donor was hindering him from the transplantation therapy. ATG and the variety of drugs that may be combined also increase the burden on the liver and the risk of infection. Avatrombopag is a thrombopoietin receptor agonists (TPO-RA) that is FDA-approved for immune thrombocytopenia (ITP) and periprocedural thrombocytopenia in patients with chronic liver disease ${ }^{[7]}$. This is the first case report for its use in severe AA to date. TPO-RA showed beneficial effect on the expansion and maintenance of hematopoietic stem cells. TPO-RA eltrombopag has been used in AA with an overall response rate of $40-50 \%$ in patients with refractory severe AA as a single agent and response rates up to $94 \%$ in newly diagnosed severe AA together with horse ATG and $\mathrm{CsA}{ }^{[8]}$. Eltrombopag has an adverse event of hepatic impairment. With its advantage of absence of hepatotoxicity, avatrombopag is a favorable option for this patient. Finally, the patient achieved response with two oral drugs of avatrombopag and low-dose CsA sparing HSCT and ATG.

Aplastic anemia with EPP is really rare and maybe a mere coincidence. Liver fibrosis associated with EPP affects the prognosis significantly. TPO-RA avatrombopag combined with CsA provide an available therapy for patients with severe aplastic anemia associated with EPP and liver fibrosis.

\section{Declarations}

\section{Acknowledgments}

We thank the families for giving consent to disclose their medical records and provide blood samples for our study.

\section{Authors' contribution}

Z.J. and M.C. provided diagnosis and treatment for the patient and wrote the manuscript. Both authors reviewed the manuscript and approved the final submission of the manuscript.

\section{Funding information}

The work was supported by the National Natural Science Foundation of China (NSFC) (81970106).

\section{Conflict of interest}

The authors declare no conflict of interest.

\section{Ethical approval}

All procedures performed in studies involving human participants were in accordance with the ethical standards of the institutional and/or national research committee and with the 1964 Helsinki declaration 
and its later amendments or comparable ethical standards.

\section{Informed consent}

Informed consent was obtained from the patient included in the study.

\section{References}

1. Balwani M. Erythropoietic Protoporphyria and X-Linked Protoporphyria: pathophysiology, genetics, clinical manifestations, and management. Mol Genet Metab. 2019 Nov;128(3):298-303. doi: 10.1016/j.ymgme.2019.01.020.

2. Meerman L. Erythropoietic protoporphyria. An overview with emphasis on the liver. Scand $\mathrm{J}$ Gastroenterol Suppl. 2000;(232):79-85. PMID: 11232498.

3. Shirota T, Yamamoto H, Hayashi $\mathrm{S}$, et al. Myelodysplastic syndrome terminating in erythropoietic protoporphyria after 15 years of aplastic anemia. Int J Hematol. 2000 Jul;72(1):44-7. PMID: 10979208.

4. Ardalan ZS, Chandran S, Vasudevan A, et al. Management of Patients With Erythropoietic Protoporphyria-Related Progressive Liver Disease. Liver Transpl. 2019 Nov;25(11):1620-1633. doi: 10.1002/It.25632. Epub 2019 Sep 30. PMID: 31469227.

5. Casanova-González MJ, Trapero-Marugán M, Jones EA, et al. Liver disease and erythropoietic protoporphyria: a concise review. World J Gastroenterol. 2010 Sep 28;16(36):4526-31. doi: 10.3748/wjg.v16.i36.4526. PMID: 20857522; PMCID: PMC2945483.

6. Bacigalupo A. How I treat acquired aplastic anemia. Blood. 2017 Mar 16;129(11):1428-1436. doi: 10.1182/blood-2016-08-693481. Epub 2017 Jan 17. PMID: 28096088.

7. Gilreath J, Lo M, Bubalo J. Thrombopoietin Receptor Agonists (TPO-RAs): Drug Class Considerations for Pharmacists. Drugs. 2021 Jul;81(11):1285-1305. doi: 10.1007/s40265-021-01553-7. Epub 2021 Jun 23. PMID: 34160821; PMCID: PMC8318934.

8. Drexler B, Passweg J. Current evidence and the emerging role of eltrombopag in severe aplastic anemia. Ther Adv Hematol. 2021 Mar 3;12:2040620721998126. doi: 10.1177/2040620721998126. PMID: 33747425; PMCID: PMC7940771.

\section{Figures}




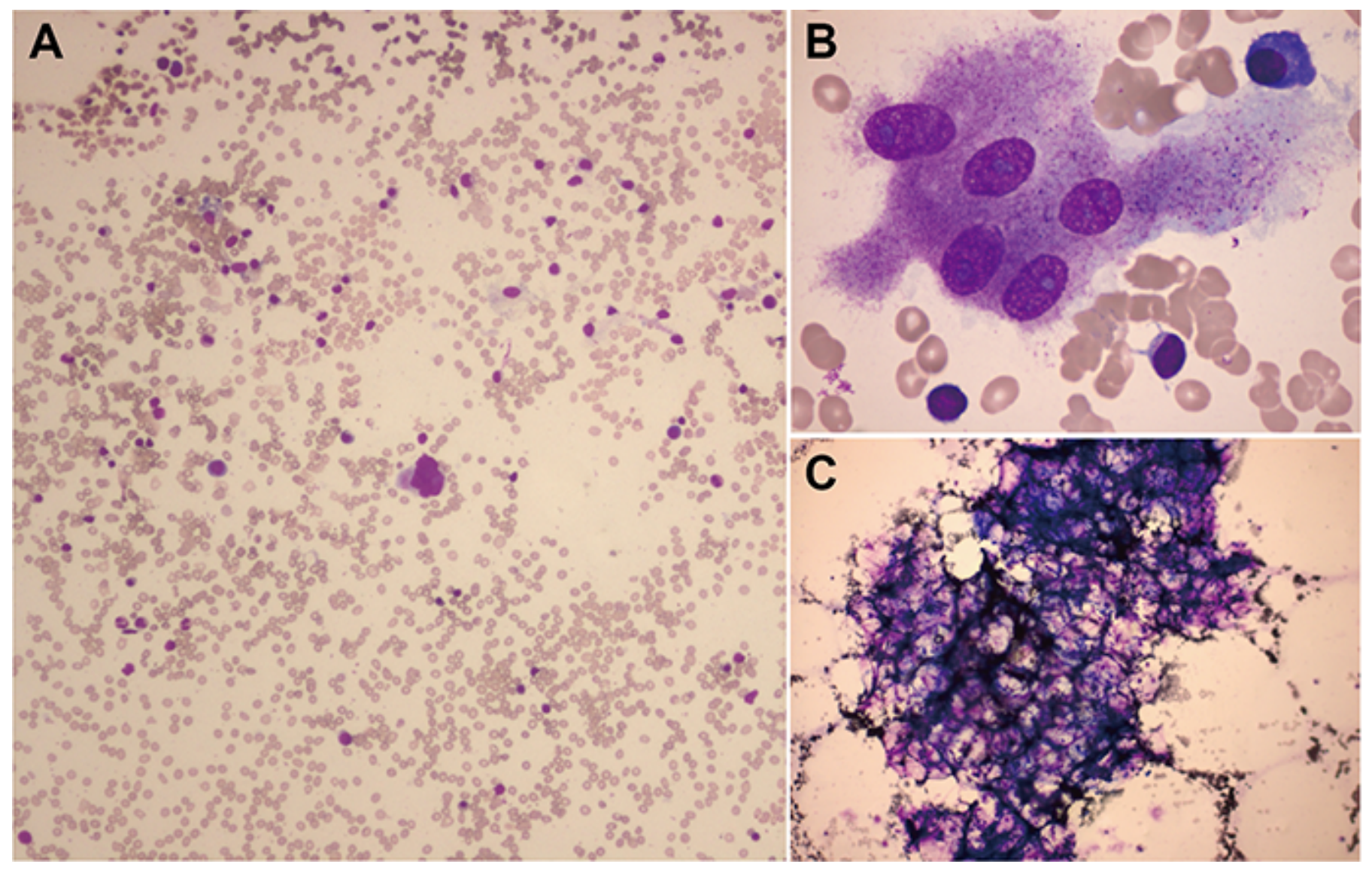

\section{Figure 1}

The bone marrow aspirate smear A. Bone marrow smear exhibited hypocellular marrow (Wright-Giemsa stain, original magnification $\triangle \times 100$ ). B. The marrow smear showed increased non-hematopoietic cells such as osteoclasts, lymphocytes and plasma cells (Original magnification, $\times 1000$ ). C. The marrow smear showed residual non-hematopoietic stroma (Original magnification, $\times 100$ ). 


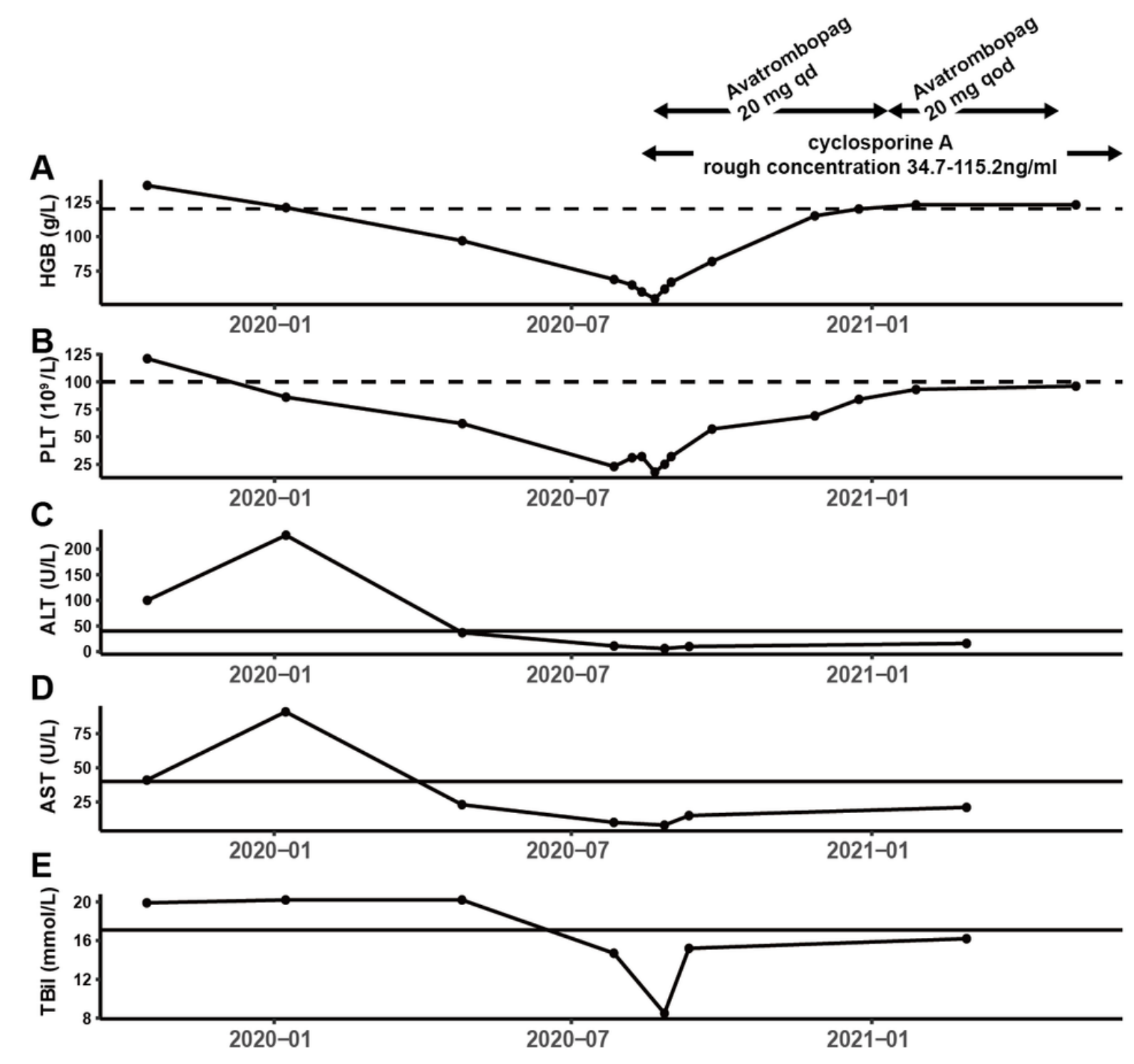

\section{Figure 2}

Graph of timeline of platelet counts, hemoglobin level and liver function tests response to avatrombopag therapy A-E, HGB = hemoglobin; PLT = platelet count; ALT = alanine aminotransferase; $\mathrm{AST}$ = aspartate aminotransferase; TBil = total bilirubin. Dotted line shows lower limits of normal and solid line showed upper limits of normal. 